\title{
The Effect of Vitamin C on the Healing of Wounds
}

\section{Dr. G. H. Bourne (University Laboratory of Physiology, Oxford) Human Scurvy}

The collection of symptoms known as scurvy and attributed particularly to a deficiency of vitamin $\mathrm{C}$ in the diet has been known for very many years. It is believed to have been mentioned in certain Egyptian papyri and to have been described by Hippocrates. The most reliable early record of it is that of de Joinville, who in 1250 wrote of its occurrence in the crusading armies of Louis IX before Cairo. Many other writers since this time have described a disease which was probably scurvy, but Echthius (1541) has given one of the earliest detailed descriptions of it. According to him, the disease is characterized by "a spongy swelling of the gums, which are apt to bleed, with a loosening of the teeth; an eruption of leaden coloured, purple or livid spots on the legs; or of somewhat broader speckled or dark coloured maculae, sometimes on the face, at other times on the legs. As the disease develops the patients lose the use of their legs and are subject to a difficulty of breathing."

Kramer (1720) and Lind (1753) also have given considerable details of this disease. In past wars scurvy has been responsible for a large number of casualties; in, for example, the American Civil War, the army of the Potomac had 30,000 cases of scurvy in five years. It was found that the characteristic early symptom of the disease in these men was pain in the joints. In the Crimean war in which scurvy and sub-scurvy were rampant, a similar symptom was found.

The early literature on scurvy shows that the disease involves two fundamental defects in the body. One is haemorrhage, and the other is the weakening of the fibrous tissues, leading to falling out of the teeth, loosening of the joints, spontaneous fracture of the bones and so on. Höjer (1924) described a widespread deficiency of collagen in the connective tissues of the body in experimental scurvy in guineapigs. It is thus obvious that, as a result of scurvy, there is a considerable degeneration of tissues already formed. One would expect, therefore, that in this disease there would be correspondingly either a complete failure to produce new tissues or the production only of defective tissues. In other words, that there would be in scurvy an incomplete healing of wounds of the hard and soft tissues of the body. This is borne out by the early clinical records in which it was stated that in scurvy wounds healed badly or not at all and old, healed wounds were liable to break open again.

Richard Walter, who was chaplain on Lord Anson's expedition round the world in 1740-44, described a number of cases on the voyage in which as a result of scurvy the scars of old wounds broke open, he claimed also that in one man whose femur had been fractured at the Battle of the Boyne, fifty years before, the fracture became soft again as a result of the disease (Walter, 1740-44).

Marrigues (1783), Bell (1788) and Callisen (1798) also claimed to have found softening of the callus of old fractures in scurvy, while Lind (1753) and Mead (1762) reported cases where healed skin wounds broke open as a result of this disease. In the American Civil War it was found that wounds, scratched insect bites and vaccination marks tended not only 
not to heal, but actually to turn into scorbutic ulcers. According to Lobmeyer (1918) skin wounds and fractures healed badly in those Turkish soldiers in the war of 1914-18 who suffered from scurvy. There are various other clinical observations on this subject but there is not the space to mention them.

It seems definitely established from clinical observation, therefore, that once scurvy has developed there is almost complete failure of regeneration of the body tissues. This is amply substantiated by experimental work on animals.

\section{Soft Tissues}

\section{Experimental Scurvy}

Ishido (1923) reported a delay in the healing of skin wounds in experimental scurvy, and Saitta (1929) obtained similar results. Other authors have found that administration of extra vitamin $\mathrm{C}$ to animals which normally synthesize their own supplies of the vitamin had no accelerating effect on the healing of skin wounds. Lanman and Ingalls (1937) found that wounds in the skin and stomach wall of guineapigs had a lower tensile strength in animals receiving small amounts of vitamin $\mathrm{C}$ than in those having ample doses. Thus, an air pressure of $160 \mathrm{~mm}$. of mercury was needed to rupture abdominal wounds in animals receiving a scorbutogenic diet supplemented with greens, while a pressure of $65 \mathrm{~mm}$. sufficed with guineapigs given a supplement of only $0.5 \mathrm{mg}$. of vitamin $\mathrm{C}$ daily. For gastric wounds the corresponding figures were 70 and $30 \mathrm{~mm}$., respectively.

These results have been confirmed by other writers. Lauber and Rosenfeld (1938) showed that when guineapigs receiving small doses of vitamin $\mathrm{C}$ were wounded, their organs lost some or all of their vitamin $\mathrm{C}$ content, presumably because of an increased demand for the vitamin, or a mobilization of it for the process. This suggests that the fact that a wound heals fairly well does not necessarily indicate that the body is receiving adequate amounts of the vitamin, since it may at the same time be using up its reserves of vitamin $\mathrm{C}$ to provide the vitamin necessary for the healing process, particularly if the intake is small and the wound extensive.

Bartlett, Jones and Ryan $(1942,1,2)$ found that the tensile strength of a wound scar was proportionate to the amount of vitamin $\mathrm{C}$ which the scar contained. For example, in guineapigs in which the scar tissues contained $7.64 \mathrm{mg}$. vitamin $\mathrm{C}$ per $100 \mathrm{~g}$. of tissue the wound burst at a pressure of $258 \mathrm{~mm}$. of mercury; in animals in which the vitamin $\mathrm{C}$ content of the scars averaged $0.31 \mathrm{mg}$. per $100 \mathrm{~g}$., the skin burst at a pressure of $127 \mathrm{~mm}$. of mercury.

Various authors, Bartlett et al. (1942, 1, 2), Wolfer and Hoebel (1939), have shown also that in patients or animals with low values for vitamin $\mathbf{C}$ in the plasma surgical wounds healed slowly. Crandon, Lund and Dill (1940) studied experimental wound healing in a human subject. After this individual had received a diet deficient in vitamin $\mathrm{C}$ for 3 months and the plasma value for vitamin $\mathrm{C}$ had been nil for 44 days, a wound made in the back showed good healing after 10 days. Ordinary histological observations showed that there was abundant intercellular sub stance and capillary formation. After about 6 months' deprivation, however, a similar wound showed no signs of healing

voL. 4,1946$]$ 
I have made a detailed study recently of the effects of graded doses of vitamin $\mathrm{C}$ on the formation of collagen fibres and on the tensile strength of wounds in groups of 9 guineapigs receiving graded doses of vitamin C (Bourne, 1944). The animals were given a scorbutogenic diet with daily supplements of $0,0 \cdot 25,0 \cdot 5,1$ or $2 \mathrm{mg}$. daily of the pure synthetic vitamin. After a week of this dietary treatment two quarter-inch cuts were made in the back of each animal on either flank, and the diet was continued for another 7 days after the operation; the animals were then killed, the pieces of skin containing the wound were removed, and tests for tensile strength were made by the simple method of supporting the skin on one side of the scar and attaching weights to it on the other side until the scar broke across. The average results are shown in Table 1.

TABLE 1

Tenstce Strenergti of Wounds in Guineapigs Given Graded Doses of Ascorbic Acid

\begin{tabular}{c|c}
\hline $\begin{array}{c}\text { Daily dose of ascorbic acid } \\
\text { mg. }\end{array}$ & $\begin{array}{r}\text { Woight at which scar broke } \\
\text { g. }\end{array}$ \\
\hline $2 \cdot 0$ & $338 \cdot 6 \pm 26 \cdot 8$ \\
$1 \cdot 0$ & $137.7 \pm 13 \cdot 9$ \\
$0 \cdot 5$ & $118 \cdot 5 \pm 19 \cdot 0$ \\
$0 \cdot 25$ & $79 \cdot 3 \pm 10 \cdot 4$ \\
$0 \cdot 0$ & $25.3 \pm 7 \cdot 4$ \\
\hline
\end{tabular}

From these results it can be seen that the tensile strength of the scar varied with the dose of vitamin $\mathrm{C}$ given.

A similar experiment was carried out on a group of animals given daily doses of $30 \mathrm{mg}$. of vitamin $\mathrm{C}$. This is sufficient for saturation, but it was found that the tensile strength of the scar was not increased over that obtained by administering $2 \mathrm{mg}$.

These results show that in guineapigs, first, pure vitamin $\mathrm{C}$ directly affects the healing and tensile strength of skin wounds, second, maximum healing and tensile strength are obtained before saturation with vitamin $\mathrm{C}$ is reached, and third, there is a decline in tensile strength before symptoms of scurvy appear.

In vitamin $\mathrm{C}$ deficiency the failure of wounds to heal properly and their lowered tensile strength are undoubtedly due to deficient production of collagen fibres. This has been shown by the work of Wolbach and Howe $(1925,1926)$ and of various other authors. Wolbach and Bessey (1942) make the following statement about the relationship of vitamin $\mathrm{C}$ to the connective tissues:

"All intercellular substances of the supporting tissues, bone, cartilage, fibrous connective tissue and dentin, have a common substructure of collagen. By collagen we wish to indicate a number of compounds of similar though not necessarily identical composition which react similarly to staining techniques. It is this protein substructure which in scurvy is either not produced or is produced in defective form."

It is known that collagen fibres when they are first formed give the same 
staining reaction as reticular fibres, and Hunt (1941) has shown that in experimental wounds in scurvy there is a delay in the transition of the reticular fibres into true collagen fibres.

In histological preparations of scar tissue from my own experiments it was found that the tensile strength of the wound varied inversely with the amount of reticular fibres in the scar. In the human experiment described by Crandon et al. (1940), it is obvious that, although the experimental wound, made after three months of a scorbutogenic diet, appeared to heal by both clinical and histological standards, it might still, if stained for reticular fibres, have shown a high proportion of these fibres and a low tensile strength.

\section{Bone}

Bone possesses a basic ground substance of fibres similar to the collagen fibres found in connective tissues. One would expect, therefore, that in vitamin $\mathrm{C}$ deficiency there would be some delay in the healing of bone, and this has been found to be the case both clinically and experimentally.

TABLE 2

The Effect of Daily Supplements of Vitakin $C$ on the Trabecular Index of Guineapigs Receiving a Scorbutogenic Diet

\begin{tabular}{c|c}
\hline $\begin{array}{c}\text { Daily dose of ascorbic acid } \\
\text { mg. }\end{array}$ & Trabecular index $\times 100$ \\
\hline $4 \cdot 0$ & $18.09 \pm 4.48$ \\
$2 \cdot 0$ & $23.73 \pm \mathbf{6 5}$ \\
1.0 & $19 \cdot 41 \pm 3 \cdot 53$ \\
0.5 & $9 \cdot 74 \pm 2 \cdot 48$ \\
0.25 & $6 \cdot 70 \pm 2.30$ \\
$0 \cdot 0$ & $7 \cdot 73 \pm 2.25$ \\
\hline
\end{tabular}

In the regeneration of bone there seems to be a delay in the absorption of cellular debris in the region of the fracture, and partial or complete failure of formation of bony trabeculae. There has been found a failure also of capillary blood vessels to penetrate into the region of the injury. No comparative figures have been obtained in the past for the relationship of bone formation to the amount of vitamin $\mathrm{C}$ in the diet, mainly because no experimental method has been devised for measuring the amount of bone formed. To provide comparative figures for this purpose, the method I adopted was to bore a small hole in each femur of a guineapig with a dentist's twist drill, with full aseptic precautions. A period of one week was allowed for healing to take place. The animals were then killed, the femur was removed and, after decalcification, sections were cut through the centre of the hole. The central sections through the hole were then projected, magnified, upon paper, and the outlines of the trabeculae were drawn. They were subsequently cut out and weighed and their weight divided by the weight of the pieces of paper equal to the total area of the hole similarly magnified in a central transverse section through the femur (Bourne, 1942-43). Full details of this method have already been described (Bourne, 1942). By this method it vot. 4, 1946] 
was possible to obtain what was described as a "trabecular index of bone regeneration"; this value was multiplied by 100 in order to provide a figure with whole numbers. The results are given in Table 2.

With doses of 1,2 and $4 \mathrm{mg}$. there was no significant difference between the values for the trabecular index but, between the values for the $1 \mathrm{mg}$. dose and the lower doses, the difference was significant. A result was thus obtained for the healing of bone similar to that obtained for the healing of skin wounds. That is to say, the formation of the collagenous material which serves as the base of the bony trabeculae was affected by vitamin $\mathrm{C}$ deficiency in the same way as the collagen which forms the scar of a skin wound.

The fact that there was no greater formation of bone in animals receiving $4 \mathrm{mg}$. of vitamin $\mathrm{C}$ than in those receiving $2 \mathrm{mg}$., indicated that the latter dose produced in bone, as in skin, the optimum amount of healing. In similar experiments with rats which synthesize their own vitamin $\mathrm{C}$, it was found that when they were injected daily with $45 \mathrm{mg}$. of vitamin $\mathrm{C}$, acceleration of healing could not be brought about. When, however, calcium ascorbate was injected instead of vitamin $C$ there was an increased production of trabeculae. Such an increased production could not be obtained when vitamin $\mathrm{C}$ and calcium gluconate were injected in separate. solutions or when calcium lactate was injected alone or with vitamin $\mathrm{C}$. It is difficult to explain this result but it may be due to the fact that calcium in the form of the ascorbate is more readily absorbed after injection than other salts of calcium, and the increased absorption of calcium may have some effect in stimulating bone formation.

Some experiments have been carried out in an attempt to ascertain whether in vitamin $\mathrm{C}$ deficiency there is also a delay in the deposition of calcium salts on the fibrous ground substance. Freshly deposited calcium in bone can be stained bright pink by injecting an animal with sodium alizarin sulphonate. Salter and Aub (1931) showed that in scorbutic guineapigs the injection of this compound failed to stain the bone pink, indicating that there was a failure of calcification of the bones. I have shown also that the pink stain round holes bored in the femur of guineapigs with scurvy is much less intense than in the femur of normal animals. This cannot be taken, however, to indicate that there is necessarily a failure of calcium deposition as such, because it is obvious that if there is deficient production of fibrous ground substance there is nothing on which the calcium can be deposited.

Examination of the costochondral junctions of normal and scorbutic guineapigs studied by von Kossa's method for demonstrating calcium, showed that, although there were fewer bony trabeculae at the junction in the scorbutic than in normal animals, those trabeculae which were formed, stained just as intensely as in the normal animal. Similarly, it was found by the use of alizarin that in the injured areas of bones, the trabeculae formed stained as deeply in scorbutic animals as in normal ones, although the number of trabeculae was less.

It has been found that osteogenetic fibres when they are produced contain alkaline phosphatase which is believed to play an important part in bone formation. In scorbutic animals there is a reduction in the total phosphatase staining in regions where bone has been injured, but individual fibres still stain as intensely as in a normal animal. It is 
suggested, therefore, that the apparent decrease of phosphatase in boneforming areas in scorbutic animals is due, not so much to the actual decrease in production of phosphatase as to reduction in the number of fibres formed.

From all the results quoted above it can be concluded that the failure of bone formation in scurvy is due actually to the failure of the production of the inorganic matrix.

There seems little doubt that deficiency of vitamin $\mathrm{C}$ will delay healing of wounds of both skin and bone; the results which have been quoted in this paper show also that delay of healing begins before there are signs that scurvy can be expected, but that saturation with the vitamin is not necessary for optimum healing.

My own work on the healing of wounds and fractures has been carried out on guineapigs and cannot, of course, be applied directly to human beings. Nevertheless, it obviously has a human application. The difficulty lies, however, in assessing what are the equivalent amounts of vitamin $\mathrm{C}$ for human beings, represented by the amounts quoted for guineapigs. If it is assumed that the minimum requirement of vitamin $\mathrm{C}$ to prevent scurvy in human beings is about $7 \mathrm{mg}$. per day, and that for guineapigs it is $0.5 \mathrm{mg}$. per day, it can be further assumed that a daily dose of about $30 \mathrm{mg}$. is required for optimum healing of wounds in human beings.

On a recent visit to Ceylon, I had described to me the details of four patients who, after abdominal operation, showed no signs of healing of the wound. They exhibited no symptoms at all of scurvy, yet three of them, when treated with orange juice, showed prompt healing of the wounds, and the fourth, who did not receive orange juice, eventually died. There was unfortunately no information available as to the vitamin $\mathrm{C}$ content of the diet of these people before the orange juice was given, but it was obviously sufficient to prevent scurvy.

It should be borne in mind in assessing the amount of vitamin $G$ needed for optimum wound healing that there is probably a very considerable individual variation in vitamin $\mathrm{C}$ requirement, that the vitamin $\mathrm{C}$ requirement of an injured man is probably greater than that of a normal human being, and that the amount of vitamin $\mathrm{C}$ required will vary according to the extent of the injuries.

\section{REFERENCES}

Bartlett, M. K., Jones, C. M. and Ryan, A. E. (1942, 1). New Engl.J. Med. 226, 469.

Bartlett, M. K., Jones, C. M. and Ryan, A. E. (1942, 2). Neqo Engl.J. Med. 226, 474.

Bell, B. (1788). A System of Surgery, Vol. 6. London.

Bourne, G. (1942). Quart. J. exp. Physiol. 31, 319.

Bourne, G. (1942-43). J. Physiol. $101,327$.

Bourne, G. H. (1944). Lancet, 246, 688.

Callisen, H. (1798). Quoted by Hertz (1936).

Crandon, T. H., Lund, C. C. and Dill, D. B. (1940). New Engl. J. Med. 223, 353.

Echthius, J. (1541). Quoted by Lind (1753).

Hertz, J. (1936). Studies on the Healing of Fractures, with Special Reference to the Significance of the Vitamin Content of the Diet. London: Oxford University Press.

Hojer, J. A. (1924). Acta Paediatr., Stockh., Suppl. 3.

Hunt, A. H. (1941). Brit. J. Surg. 28, 436.

vor. 4,1946$]$ 
Ishido, B. (1923). Virchows Arch. 240, 241.

Kramer, J. G. (1720). Quoted by Lind (1753).

Lanman, T. H. and Ingalls, T. H. (1937). Ann. Surg. 105, 616.

Lauber, H. J. and Rosenfeld, W. (1938). Klin. Wschr. 17, 1587.

Lind, J. (1753). A Treatise on the Scurvy. London.

Lobmeyer, G. (1918). Dtsch. med. Wschr. 44, 557.

Marrigues, A. (1783). Quoted by Hertz (1936).

Mead, R. (1762). Medical Works. London.

Saitta, S. (1929). Scr. biol. L. Castaldi, 4, 301.

Salter, W. J. and Aub, J. C. (1931). Arch. Path. 11, 380.

Walter, R. (1740-44). A Voyage Round the World. London: John and Paul Knapton.

Wolbach, S. B. and Bessey, O. A. (1942). Physiol. Rev. 22, 233.

Wolbach, S. B. and Howe, P. R. (1925). Proc. Soc. exp. Biol., N.Y., 22, 400.

Wolbach, S. B. and Howe, P. R. (1926). Arch. Path. 1, 1.

Wolfer, J. A. and Hoebel, F. C. (1939). Surg. Gynec. Obstet. 69, 745.

\section{General Discussion}

Professor J. R. Learmonth (Department of Surgery, University New Buildings, Edinburgh): With regard to Dr. Cuthbertson's paper, it seems to me that there would be an opportunity for studying the dispersal of nitrogen from muscle, in nerve injuries which involve a nerve of the upper $\operatorname{limb}$, particularly the musculo-spiral nerve whose division is followed by a rapid reduction in bulk of the extensor-supinator group of muscles, not contributed to by disuse from confinement to bed. I wonder also whether some information about the possible importance, use and fate of various amino-acid groups could be obtained by the use of tagged ions.

There are one or two clinical points that occur to me. It seemed to me that at the beginning of the war, with the dietary restrictions envisaged, there might be some difficulty in surgical practice with regard to the healing of wounds, and I have kept a record of the time spent in hospital after various major operations. The time spent in hospital has not been affected by war time diets.

There is one point with regard to the disruption of wounds; a great many factors are apparent to the clinician which are possibly not apparent to other workers in studies of this sort. In the first place, in the study of the disruption of a wound, the normal tensile strength of the tissue which is sutured should form an integral part of the preliminary consideration for the work, as well as the tensile strength of the suture material, which should not exceed the tensile strength of the tissue to be sutured. The type of suture employed should always be taken into consideration because it is important to know the effect of knots on tensile strength; a mattress suture, for instance, has a different tensile strength from a figure-of-eight suture.

In human work we are faced with a further difficulty that certain people seem to be peculiarly susceptible to certain forms of suture materal. Some patients are "anaphylactic" to catgut, and wounds may break down when closed with this material. The materials used to harden sutures, such as chromic and tannic acids, may have an effect on the wound, and they vary from brand to brand. That ought always to be accurately assessed beforehand.

An interesting point is that if an abdominal wound bursts open, the second suture of the wound is usually attended by secure healing. There 